\title{
Effect of daily supplementation of soy isoflavones on hot flashes and night sweats in African menopausal women
}

\author{
Ronbinson Enow Mbu ${ }^{1 *}$, Yao Raphaël Abauleth ${ }^{2}$, Akpadza Koffi $^{3}$, Namory Keita ${ }^{4}$, Amadou Dolo ${ }^{5}$, \\ Jean Lankoande ${ }^{6}$ \\ ${ }^{1}$ Department of Obstetrics and Gynecology, Faculty of Medicine and Biomedical Sciences, University of Yaounde 1, Yaounde, Cameroun \\ ${ }^{2}$ Department of Obstetrics and Gynecology, Cocody University and Hospital, Boulevard de l’Université de Cocody, Abidjan, Côte \\ d'Ivoire \\ ${ }^{3}$ Department of Obstetrics and Gynecology, Tokoin University Hospital, 198 rue de l’hôpital, Lome, Togo \\ ${ }^{4}$ Department of Obstetrics and Gynecology, University of Conakry and DONKA Hospital, Conakry, Republique de Guinée \\ ${ }^{5}$ Department of Obstetrics and Gynecology, Gabriel Touré University Hospital, Bamako, Mali \\ ${ }^{6}$ Department of Obstetrics and Gynecology, Yalgado Ouédraogo University Hospital, Avenue du capitaine Thomas Sankara, Ouaga- \\ dougou, Burkina Faso \\ Email: rembu2000@yahoo.com, abauleth@hotmail.com, namoryk2010@yahoo.fr, namory.keita@guinea-medical.org
}

Received 7 November 2013; revised 7 December 2013; accepted 15 December 2013

Copyright (C) 2014 Ronbinson Enow Mbu et al. This is an open access article distributed under the Creative Commons Attribution License, which permits unrestricted use, distribution, and reproduction in any medium, provided the original work is properly cited. In accordance of the Creative Commons Attribution License all Copyrights (c) 2014 are reserved for SCIRP and the owner of the intellectual property Ronbinson Enow Mbu et al. All Copyright (C 2014 are guarded by law and by SCIRP as a guardian.

\section{ABSTRACT}

The aim of this study was to evaluate the effectiveness of a pharmaceutical grade isoflavone supplement (Inoclim $^{\circledR}$ ) $40 \mathrm{mg}$ per capsule of soy extract rich in daidzin and genistin) on the number of hot flashes and night sweats in menopausal African women. This open, prospective, multicenter study involved 140 menopausal women with climacteric symptoms (i.e., a minimum of five hot flashes and/or moderate to severe night sweats per day). These patients received a daily $40-\mathrm{mg}$ supplement of soy isoflavone contained in an Inoclim ${ }^{\circledR}$ capsule (Laboratoire Innotech International, France). The dose was increased to two capsules per day when there were more than five hot flashes or when the women could not sleep because of night sweats. The patients were followed up over a 4-month period and data were analyzed using EPI-Info ${ }^{\mathrm{TM}}$ version 3.5.1. The outcome measure was fewer hot flashes and night sweats. The mean daily number of episodes of hot flashes was 5.7 at baseline and 1.8 at week 16 , corresponding to a decrease of $68.4 \%(n=93$ patients at baseline and $n=66$ at 16 weeks). The mean number of daily episodes of night sweats was 3.7 at baseline and 0.8 at week 16, corresponding to a decrease of $78.4 \%(n=127$ patients in the first week and $n=73$ at 16 weeks). Over $80 \%$ of patients took a single one 40 mg capsule per day. The percentage of patients who

\footnotetext{
"Corresponding author.
}

adhered to the prescription was more than $95 \%$ during the 4-month follow-up period. These results confirm the effectiveness of a pharmaceutical grade isoflavone supplement (40 mg, rich in genistin and daidzin) on vasomotor symptoms in menopausal women.

\section{KEYWORDS}

Menopause; Climacteric Disorders; Hot Flashes; Night Sweats; Soy Isoflavones; Genistin, Daidzin; Genistein; Daidzein; Inoclim

\section{INTRODUCTION}

The most common symptoms associated with menopause include vasomotor instability, decreased libido, vaginal dryness, insomnia, and bone or joint disorders. Hot flashes are a vasomotor response to estrogen deficiency, which generally appears up to five years after the end of menstruation, and lasts for at least one year [1]. Hot flashes and sweating are estimated to affect $80 \%$ of the female population in Western countries. However, this prevalence is lower in Southeast Asian populations [2]. With regard to African women, few studies are available in the relevant literature, and those that exist mainly reflect a lack of information on menopause (e.g., symptoms and available treatments) [3-7]. The prevalence of climacteric disorders varies according to studies from $57 \%$ to $85 \%$, and their management remains inadequate [4-6]. In addition, the age of menopause onset seems to be slightly hi- 
gher for African women compared to the rest of the world (between 48 and 49 years on average).

Menopausal women often consider hot flashes to be the most difficult symptom to tolerate. These vasomotor-related effects can greatly impact the quality of life [8]. Hormone replacement therapy (HRT) remains the most effective treatment for vasomotor instability during menopause [9]. Nevertheless, treatment approaches must be personalized by evaluating the risk/benefit balance for each patient and taking into account certain risk factors, including breast cancer, coronary events, stroke, and thromboembolism. Indeed, several studies have suggested that long-term HRT increases the risk of breast cancer, ovarian cancer, endometrial cancer, and stroke [9]. This explains the high demand for non-hormonal treatments for menopausal disorders [10]. Isoflavones are substances that have an affinity for estrogen receptors, although they are chemically non-steroidal $[11,12]$. Their safety in humans has already been demonstrated in previous studies [13]. However, findings related to their effects on menopausal symptoms have been at times contradictory due to the variety of isoflavones and standardization of doses. The two main soy isoflavones are daidzin and genistin. They are transformed within the intestinal tract into biologically active compounds, daidzein and genistein. The chemical structure of genistein and daidzein is similar to that of $17 \beta$-estradiol, which allows them to bind estrogen receptors, but with a relatively low affinity [14]. The Inoclim ${ }^{\circledR}$ formulation (Laboratoire Innotech International, France), which contains $40 \mathrm{mg}$ of soy isoflavones, has not been evaluated in the context of climacteric disorders. Therefore, the goal of this study was to evaluate the effect of Inoclim $^{\circledR}$ on hot flashes and night sweats in menopausal African women.

\section{METHODS}

This was a prospective, open, and multicenter study carried out on menopausal women with hot flashes and/or night sweats. During the 16-week study, the patients received a daily supplement of one $\operatorname{Inoclim}^{\circledR}$ capsule (Laboratoire Innotech International, France), which contained $40 \mathrm{mg}$ of soy isoflavones. In some cases, the dose was increased to two capsules per day, when deemed necessary by the investigator.

To be included in the study, patients had to be menopausal for at least one year and to experience at least five episodes of hot flashes per day and/or moderate to severe night sweats every day. Exclusion criteria were women with ongoing hormonal treatment (i.e., taken in the last six weeks) or a history of hormone-dependent cancer (i.e., breast, uterus, ovarian).

A total of 270 patients were included in 10 countries (Benin, Burkina Faso, Cameroon, Congo-Brazzaville, Ivory Coast, Gabon, Guinea, Mali, Mauritius, and Togo).
During the selection or inclusion visit, patients were informed of the study both orally and in writing. Also, a general and gynecological clinical examination was performed. Appointments were scheduled at the end of every month for four months (i.e., three follow-up visits and one end-of-trial visit). Each patient recorded information regarding hot flashes and night sweats in an individual journal. Additionally, every patient signed an informed consent form before the beginning of the study, which was carried out in accordance with the latest version of the Helsinki Declaration on recommendations for biomedical research.

Evaluation criteria included the number of hot flashes and daily episodes of night sweats during the study. The data collected on hot flashes and night sweats were daily, but were grouped per week for analysis. We entered data into spread sheets and analyzed using EPI-Info ${ }^{\mathrm{TM}}$ version 3.5.1. We calculated mean number of hot flashes and/or daily night sweats during the 16 weeks of the study and represented these graphically using Excel spread sheet. Only women who finished the study were included in the effectiveness analysis.

\section{RESULTS}

Altogether, 241 patients were included in the study. The mean age was 51 years old (range: 38 - 66 years). Among them, 9.2\% had a personal history of cardiovascular disease. At the end of the four-month study period, the complete files (observation notebook and patient follow-up journal) for 140 patients were analyzed. The other patients were lost to follow-up due to unusable files or because they had chosen to discontinue treatment.

In accordance with the study protocol, patients who were not followed up for at least three months were not included in the final analysis of treatment effectiveness. A progressive decrease in the number of hot flashes and night sweats was observed during the 16 weeks of follow-up (Figure 1). Overall, the mean number of hot flashes and/or night sweats went from 9.4 at baseline to 2.6 after four months of treatment, which is an overall decrease of $72.3 \%$. Since not all patients experienced hot flashes and night sweats simultaneously, the data for each symptom could be analyzed separately. The mean number of daily hot flashes was 5.7 at baseline ( $\mathrm{n}=93$ patients) and 1.8 at week $16(n=66)$, which is a decrease of $68.4 \%$. The mean number of daily night sweats was 3.7 at baseline ( $\mathrm{n}=127$ patients) and 0.8 at 16 weeks ( $\mathrm{n}$ $=73$ ), which constitutes a decrease of $78.4 \%$.

The percentage of patients who adhered to the prescriptions was greater than $95 \%$ during the four months of follow-up, with more than $80 \%$ of patients remaining on one capsule per day.

The product was well tolerated. In fact, discontinua- 


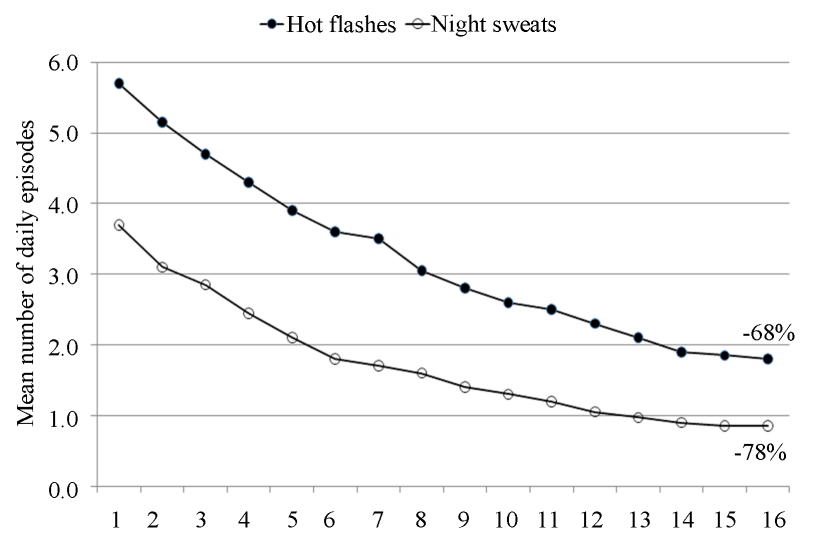

Figure 1. Mean number of hot flashes and/or daily night sweats during the 16 weeks of the study $(n=140)$.

tions due to adverse effects were rare, occurring in five patients at the one-month follow-up visit (palpitations, dizziness, high blood pressure, skin allergy) and in two patients at the two-month follow-up (stomach pain, psychiatric disorders). The contribution of Inoclim ${ }^{\circledR}$ treatment to these adverse effects was not evaluated.

\section{DISCUSSION}

Our study was carried out with pharmaceutical grade soy extract, which was rich in daidzin and genistin. During the four months of the study, we observed a gradual decrease in hot flashes (68.4\% at 16 weeks) and night sweats ( $78.4 \%$ at 16 weeks). Notably, the daily dose was adhered to by more than $95 \%$ of women throughout the study. In addition, more than $80 \%$ of the patients received only one capsule per day of isoflavone-rich soy extract (40 mg/day) and did not feel the need to increase the daily dose. Mixed results have been reported in clinical studies that examined the effects of dietary intake of soy or isoflavone supplements on hot flashes [15-29]. These inconsistent findings could be explained by the diversity of products studied, the origin of the extracts, the composition/dosage of isoflavones (particularly daidzein), the number of hot flashes at baseline, and individual metabolism (e.g., equol production) [30-34]. According to The North American Menopause Society, treatment of vasomotor symptoms using isoflavones can be achieved with an initial dose of $50 \mathrm{mg} /$ day for at least 12 weeks [34]. Here, we demonstrated that a 40-mg daily dose with Inoclim ${ }^{\circledR}$ was sufficient to reduce climacteric disorders for $80 \%$ of patients. However, this study had some limitations. Besides being an open study, problems related to completing the study documents (i.e., non-standardized completion, difficulty in maintaining regular followup) made analysis of the results complex. Nevertheless, our findings have contributed essential data to the limited information that exists regarding menopausal women in Africa, which has mostly come from prospective, open, and/or descriptive studies [3-7]. We propose that a future comparative study should be carried out, involving placebo control, a robust protocol, and a coherent follow-up that incorporates usual management of African patients.

Our results are consistent with studies that have been carried out in other regions. Indeed, Taku's meta-analysis, which included 36 comparative studies vs. placebo, showed a statistically significant decrease of $20.6 \%$ in the frequency of hot flashes $(p<0.00001)$, as well as a $26.2 \%$ reduction in their severity $(\mathrm{p}=0.001)$, using a mean dose of isoflavones of $54 \mathrm{mg} /$ day for six weeks to 12 months [24]. Furthermore, Upmalis et al. compared the efficacy of $50 \mathrm{mg}$ of genistin plus daidzin to placebo in a randomized, double-blind study [25]. After six weeks, the number of daily night sweats had decreased by $60 \%$ in the genistin plus daidzin group and by $25 \%$ in the placebo group ( $<<0.04)$. The severity of hot flashes had also decreased after 12 weeks by $27 \%$ in the genistin plus daidzin group and by $19 \%$ in the placebo group $(\mathrm{p}=$ 0.01 ). Another randomized, double-blind study by Crisafulli et al. compared HRT ( $1 \mathrm{mg} /$ day of $17 \beta$-estradiol and $0.5 \mathrm{mg}$ of norethisterone acetate) to $54 \mathrm{mg} /$ day of genistein and to placebo [26]. As expected, it was observed that HRT, which remains the standard therapy for climacteric disorders, reduced the number of hot flashes by 92\% after 12 months of treatment, whereas the placebo led to only a $19 \%$ reduction. The effect of genistein, which led to a $55 \%$ decrease in hot flashes, confirmed the efficacy of isoflavones ( $\mathrm{p}<0.01 \mathrm{vs}$. placebo). Notably, there was a $50 \%$ decrease in hot flashes after the third month of treatment with genistein. In Cheng's randomized, double-blind study against placebo, a 57\% reduction ( $p<0.01$ ) in hot flashes was observed after three months of treatment with isoflavones (60 mg/day) [27]. Additionally, D'Anna's randomized, double-blind study against placebo led to decreased hot flashes following one month of genistein treatment (54 mg/day) and reached a peak effect after 12 months (56.4\% reduction; $\mathrm{p}<$ $0.001)$ [28]. Finally, a $51 \%$ decrease $(p=0.049)$ in the number of hot flashes was observed following genistein treatment (30 mg/day for 12 weeks) in Evans's randomized, double-blind, multicenter study [29].

Taken together, a four-month treatment with Inoclim ${ }^{\circledR}$ was well tolerated by menopausal patients in our study. However, the contribution of this supplement to potential adverse effects was not evaluated. Nevertheless, the fact that isoflavones were well tolerated seems to confirm previous comparative, double-blind studies indicating no differences in the frequency of adverse events between isoflavone-treated and placebo groupsHowes [35-41].

\section{CONCLUSIONS}

These results confirm the efficacy of a pharmaceutical grade isoflavone supplement (Inoclim ${ }^{\circledR}, 40 \mathrm{mg}$ ), which is 
rich in genistin and daidzin, on vasomotor disorders in menopausal African patients. Specifically, we found that Inoclim $^{\circledR}$ treatment led to a significant decrease in the number of hot flashes and night sweats while displaying very good long-term tolerance.

\section{LIMITATIONS}

This study was based on two climacteric symptoms whereas about forty of such symptoms have been described. It was not randomized and controlled using a placebo thus findings may not be conclusive. Some participants received two capsules but analyses were not based on the number of capsules received. As it was a longitudinal symptom-based trial, the biochemistry of plasma estrogens should be combined with such analyses in future trials

\section{REFERENCES}

[1] Nelson, H.D. (2008) Menopause. Lancet, 371, 760-770. http://dx.doi.org/10.1016/S0140-6736(08)60346-3

[2] Gold, E.B., Colvin, A., Avis, N., Bromberger, J., Greendale, G.A., Powell, L., et al. (2006) Longitudinal analysis of the association between vasomotor symptoms and race/ ethnicity across the menopausal transition: Study of women's health across the nation. American Journal of Public Health, 96, 1226-1235.

http://dx.doi.org/10.2105/AJPH.2005.066936

[3] Anolue, F.C., Dike, E., Adogu, P. and Ebirim, C. (2012) Women's experience of menopause in rural communities in Orlu, Eastern Nigeria. International Journal of Gynecology \& Obstetrics, 118, 31-33. http://dx.doi.org/10.1016/j.ijgo.2012.02.014

[4] Ande, A.B., Omu, O.P., Ande, O.O. and Olagbuji, N.B. (2011) Features and perceptions of menopausal women in Benin City, Nigeria. Annals of African Medicine, 10, 300304. http://dx.doi.org/10.4103/1596-3519.87048

[5] Odiari, E.A. and Chambers, A.N. (2012) Perceptions, attitudes, and self-management of natural menopausal symptoms in ghanaian women. Health Care Women International, 33, 560-574. http://dx.doi.org/10.1080/07399332.2012.655393

[6] Nkwo, P.O. (2009) Suboptimal management of severe menopausal symptoms by Nigerian Gynaecologists: A call for mandatory continuing medical education for physiccians. BMC Women's Health, 9, 30. http://dx.doi.org/10.1186/1472-6874-9-30

[7] Sidibe, E.H. (2005) Menopause in Africa. Annals of Endocrinology (Paris), 66, 105-107.

[8] Rodstrom, K., Bengtsson, C., Lissner, L., Milsom, I., Sundh, V., Bjorkelund, C.A. (2002) longitudinal study of the treatment of hot flushes: The population study of women in Gothenburg during a quarter of a century. Menopause, 9, 156-161. http://dx.doi.org/10.1097/00042192-200205000-00003

[9] Eden, J. (1998) Phytoestrogens and the menopause. Bail- lière's Clinical Endocrinology and Metabolism, 12, 581587. http://dx.doi.org/10.1016/S0950-351X(98)80005-0

[10] Ewies, A.A. (2002) Phytoestrogens in the management of the menopause: Up-to-date. Obstetrical \& Gynecological Survey, 57, 306-313. http://dx.doi.org/10.1097/00006254-200205000-00023

[11] Albertazzi, P. and Purdie, D. (2002) The nature and utility of the phytoestrogens: A review of the evidence. $M a$ turitas, 42, 173-185. http://dx.doi.org/10.1016/S0378-5122(02)00024-5

[12] Kuiper, G.G., Lemmen, J.G., Carlsson, B., Corton, J.C., Safe, S.H., van der Saag, P.T., van der Burg, B. and Gustafsson, J.A. (1998) Interaction of estrogenic chemicals and phytoestrogens with estrogen receptor beta. Endocrinology, 139, 4252-4263. http://dx.doi.org/10.1210/en.139.10.4252

[13] Markiewicz, L., Garey, J., Adlercreutz, H. and Gurpide, E. (1993) In vitro bioassays of non-steroidal phytoestrogens. The Journal of Steroid Biochemistry and Molecular Biology, 45, 399-405. http://dx.doi.org/10.1016/0960-0760(93)90009-L

[14] Campagnoli, C., Abba, C., Ambroggio, S., Peris, C., Perona, M. and Sanseverino, P. (2005) Polyunsaturated fatty acids (PUFAs) might reduce hot flushes: An indication from two controlled trials on soy isoflavones alone and with a PUFA supplement. Maturitas, 51, 127-134. http://dx.doi.org/10.1016/j.maturitas.2004.11.002

[15] Petri Nahas, E., Nahas Neto, J., De Luca, L., Traiman, P., Pontes, A. and Dalben, I. (2004) Benefits of soy germ isoflavones in postmenopausal women with contraindication for conventional hormone replacement therapy. Maturitas, 48, 372-380. http://dx.doi.org/10.1016/j.maturitas.2003.09.026

[16] Penotti, M., Fabio, E., Modena, A.B., Rinaldi, M., Omodei, U. and Vigano, P. (2003) Effect of soy-derived isoflavones on hot flushes, endometrial thickness, and the pulsatility index of the uterine and cerebral arteries. Fertility and Sterility, 79, 1112-1117. http://dx.doi.org/10.1016/S0015-0282(03)00158-4

[17] Nikander, E., Kilkkinen, A., Metsa-Heikkila, M., Adlercreutz, H., Pietinen, P., Tiitinen, A., et al. (2003) A randomized placebo-controlled crossover trial with phytoestrogens in treatment of menopause in breast cancer patients. Obstetrics \& Gynecology, 101, 1213-1220. http://dx.doi.org/10.1016/S0029-7844(03)00232-1

[18] Faure, E.D., Chantre, P. and Mares, P. (2002) Effects of a standardized soy extract on hot flushes: A multicenter, double-blind, randomized, placebo-controlled study. $\mathrm{Me}$ nopause, 9, 329-334. http://dx.doi.org/10.1097/00042192-200209000-00005

[19] Anupongsanugool, E., Teekachunhatean, S., Rojanasthien, N., Pongsatha, S. and Sangdee, C. (2005) Pharmacokinetics of isoflavones, daidzein and genistein, after ingestion of soy beverage compared with soy extract capsules in postmenopausal Thai women. BMC Clinical Pharmacology, 5, 2. http://dx.doi.org/10.1186/1472-6904-5-2

[20] Baber, R.J., Templeman, C., Morton, T., Kelly, G.E. and West, L. (1999) Randomized placebo-controlled trial of an isoflavone supplement and menopausal symptoms in 
women. Climacteric, 2, 85-92. http://dx.doi.org/10.3109/13697139909025571

[21] Murkies, A.L., Lombard, C., Strauss, B.J., Wilcox, G., Burger, H.G. and Morton, M.S. (1995) Dietary flour supplementation decreases post-menopausal hot flushes: Effect of soy and wheat. Maturitas, 21, 189-195. http://dx.doi.org/10.1016/0378-5122(95)00899-V

[22] Scambia, G., Mango, D., Signorile, P.G., Anselmi Angeli, R.A., Palena, C., Gallo, D., et al. (2000) Clinical effects of a standardized soy extract in postmenopausal women: a pilot study. Menopause, 7, 105-111. http://dx.doi.org/10.1097/00042192-200007020-00006

[23] Washburn, S., Burke, G.L., Morgan, T. and Anthony, M. (1999) Effect of soy protein supplementation on serum lipoproteins, blood pressure, and menopausal symptoms in perimenopausal women. Menopause, 6, 7-13. http://dx.doi.org/10.1097/00042192-199906010-00004

[24] Miksicek, R.J. (1994) Interaction of naturally occurring nonsteroidal estrogens with expressed recombinant human estrogen receptor. The Journal of Steroid Biochemistry and Molecular Biology, 49, 153-160. http://dx.doi.org/10.1016/0960-0760(94)90005-1

[25] Kuiper, G.G., Carlsson, B., Grandien, K., Enmark, E., Haggblad, J., Nilsson, S., et al. (1997) Comparison of the ligand binding specificity and transcript tissue distribution of estrogen receptors alpha and beta. Endocrinology, 138, 863-870. http://dx.doi.org/10.1210/en.138.3.863

[26] Upmalis, D.H., Lobo, R., Bradley, L., Warren, M., Cone, F.L. and Lamia, C.A. (2000) Vasomotor symptom relief by soy isoflavone extract tablets in postmenopausal women: A multicenter, double-blind, randomized, placebocontrolled study. Menopause, 7, 236-242. http://dx.doi.org/10.1097/00042192-200007040-00005

[27] Colacurci, N., Zarcone, R., Borrelli, A., De Franciscis, P., Fortunato, N., Cirillo, M., et al. (2004) Effects of soy isoflavones on menopausal neurovegetative symptoms. $\mathrm{Mi}$ nerva Ginecology, 56, 407-412.

[28] Crisafulli, A., Marini, H., Bitto, A., Altavilla, D., Squadrito, G., Romeo, A., et al. (2004) Effects of genistein on hot flushes in early postmenopausal women: A randomized, double-blind EPT- and placebo-controlled study. $\mathrm{Me}$ nopause, 11, 400-404.

http://dx.doi.org/10.1097/01.GME.0000109314.11228.E5

[29] Agence nationale de sécurité sanitaire de l'alimentation, de l'environnement et du travail. Mars (2005) Sécurité et bénéfices des phyto-estrogènes apportés par l'alimentation-Recommandations. http://www.anses.fr/sites/default/files/documents/NUT-S y-phytoestrogenes.pdf

[30] Williamson-Hughes, P.S., Flickinger, B.D., Messina, M.J. and Empie, M.W. (2006) Isoflavone supplements containing predominantly genistein reduce hot flash symptoms:
A critical review of published studies. Menopause, 13, 831-839.

http://dx.doi.org/10.1097/01.gme.0000227330.49081.9e

[31] Howes, L.G., Howes, J.B. and Knight, D.C. (2006) Isoflavone therapy for menopausal flushes: A systematic review and meta-analysis. Maturitas, 55, 203-211.

http://dx.doi.org/10.1016/j.maturitas.2006.03.008

[32] Albertazzi, P., Pansini, F., Bonaccorsi, G., Zanotti, L., Forini, E. and De Aloysio, D. (1998) The effect of dietary soy supplementation on hot flushes. Obstetrics \& Gynecology, 91, 6-11.

http://dx.doi.org/10.1016/S0029-7844(97)00597-8

[33] Han, K.K., Soares Jr., J.M., Haidar, M.A., de Lima, G.R. and Baracat, E.C. (2002) Benefits of soy isoflavone therapeutic regimen on menopausal symptoms. Obstetrics \& Gynecology, 99, 389-394. http://dx.doi.org/10.1016/S0029-7844(01)01744-6

[34] NAMS (2011) 2011 isoflavones report. Menopause, 18, 732-753.

[35] Taku, K. (2012) Extracted or synthesized soybean isoflavones reduce menopausal hot flash frequency and severity: Systematic review and meta-analysis of randomized controlled trials. Menopause, 19, 1-15. http://dx.doi.org/10.1097/gme.0b013e3182410159

[36] Cheng, G. (2007) Isoflavone treatment for acute menopausal symptoms. Menopause, 14, 468-473. http://dx.doi.org/10.1097/GME.0b013e31802cc7d0

[37] D’Anna, R. (2007) Effects of the phytoestrogen genistein on hot flushes, endometrium, and vaginal epithelium in postmenopausal women: A 1-year randomized, doubleblind, placebo-controlled study. Menopause, 14, 648-655. http://dx.doi.org/10.1097/01.gme.0000248708.60698.98

[38] Evans, M. (2011) The effect of synthetic genistein on menopause symptom management in healthy postmenopausal women: A multi-center, randomized, placebo-controlled study. Maturitas, 68, 189-196.

http://dx.doi.org/10.1016/j.maturitas.2010.11.012

[39] Védrine, N. (2006) One-month exposure to soy isoflavones did not induce tha ability to produce equol in postmenopausal women. European Journal of Clinical Nutrition, 60, 1039-1045. http://dx.doi.org/10.1038/sj.ejcn.1602415

[40] (2012) The 2012 hormone therapy position statement of the North American menopause society. Menopause, 19, 257-271.

[41] Cassidy, A. (1999) Potential tissue selectivity of dietary phytoestrogens and estrogens. Current Opinion in Lipidology, 10, 47-52. http://dx.doi.org/10.1097/00041433-199902000-00009 